\title{
Insulin gene transfer enhances the function of human islet grafts
}

\author{
S. Deng 1 , M. Vatamaniuk ${ }^{2}$, M.-M. Lian' ${ }^{1}$, N. Doliba ${ }^{2}$, J. Wang ${ }^{1}$, E. Bell ${ }^{2}$, B. Wolf ${ }^{2}$, S. Raper ${ }^{1}$, \\ F. M. Matschinsky², J. F. Markmann ${ }^{1}$ \\ ${ }^{1}$ The Harrison Department of Surgical Research, Hospital of the University of Pennsylvania, \\ University of Pennsylvania Health System, Philadelphia, Pennsylvania, USA \\ ${ }^{2}$ The Penn Diabetes Center, Hospital of the University of Pennsylvania, \\ University of Pennsylvania Health System, Philadelphia, Pennsylvania, USA
}

\section{Abstract}

Aims/hypothesis. Recent success in islet transplantation renews the hope for the complete cure of patients afflicted with Type 1 diabetes. However, in the Edmonton series, two to four pancreas donors were required to obtain a sufficient islet mass to reverse the diabetes of each patient. In view of the donor shortage, this represents a major obstacle preventing greater application of islet transplantation to diabetic patients. We hypothesised that increasing the expression of the insulin gene in transplanted islets would augment their capacity for insulin production, thereby allowing reversal of diabetes with a reduced islet mass.

Methods. We used a replication defective adenovirus to deliver the human proinsulin gene (Ad-Ins) to isolated human islets. The function of Ad-Ins-transduced human islets was compared to islets transduced with a control vector (Ad-lacz).

Results. Ad-Ins-transduced islets produced two to three times more insulin than normal islets or those infected with Ad-lacz, as assessed by in vitro perifusion tests of glucose stimulated insulin release. When transplanted, Ad-Ins-transduced islets normalised the blood glucose of diabetic immunodeficient NOD-Scid mice, and less than half as many Ad-Ins islets were required for reversal of diabetes than when normal islets were transplanted.

Conclusion/interpretation. Our results suggest a simple and effective approach that could enhance the efficiency of islet transplantation for treatment of diabetes in humans. [Diabetologia (2003) 46:386-393]

Keywords Diabetes, islet, transplantation, insulin gene, adenovirus.
Renewal of insulin secretory capacity by transplantation of isolated pancreatic islets is a conceptually attractive therapy for patients afflicted with Type 1 diabetes. The recent finding that diabetes can consistently be reversed by this method, has rejuvenated interest in

Received: 3 June 2002 / Revised: 6 November 2002

Published online: 7 March 2003

C) Springer-Verlag 2003

Corresponding author: J. F. Markmann MD PhD, Department of Surgery, 4th Floor Silverstein, Hospital of the University of Pennsylvania, University of Pennsylvania Health System, 3400 Spruce Street, PA 19104 Philadelphia, USA

E-mail: james.markmann@UPHS.upenn.edu

Abbreviations: NOD, Non-obese diabetic; Scid, severe combined immunodeficiency; Ad-INS, adenovirus-insulin vector; Ad-lacz, adenovirus-beta-galactosidase vector; IEq, islet equivalents. islet transplantation as a potentially widely applicable treatment $[1,2]$. The reason for the unprecedented success seen in the Edmonton series after so many failed attempts by other investigators is not completely understood, but probably depends in part on the use of a novel, steroid-free immunosuppressive regimen in conjunction with infusion of a large mass of islets (>9000 Islet equivalents $/ \mathrm{kg}$ of recipient body weight). One aspect of this protocol which is of practical concern, is that to achieve an islet transplant mass greater than 9000 IEq's per $\mathrm{kg}$ of recipient body weight (the apparent threshold for success), islets isolated from two to four cadaveric donor pancreata were required.

A multi-centre trial is now under way to confirm the encouraging results reported using the Edmonton protocol. If others can corroborate the efficacy of the procedure, a major obstacle limiting the widespread 
application of islet transplantation for the treatment of diabetes will be inadequate numbers of donor islets. This limitation is evident because there are already more than 1 million Type 1 diabetic patients in the United States alone and 50000 are newly diagnosed each year; in contrast the cadaveric pancreas supply is nearly static at about 5500 a year. Since chronic immunosuppression to prevent graft rejection would be necessary, the benefits of the procedure would not outweigh the risks in all diabetic patients. Nevertheless, if even in $1 \%$ of cases the indications were sufficient to justify transplantation, improving the efficiency of the procedure and reducing the number of donor islets needed for successful transplantation would increase the number of patients who could benefit from this therapy $[3,4]$.

We explored a new approach designed to reduce the number of islets required for the restoration of glucose homeostasis after islet transplantation by increasing the efficiency of islet function in terms of insulin synthesis and secretion. To accomplish this, we transferred the human proinsulin gene directly into isolated pancreatic islet cells using an adenoviral vector known to provide high efficiency islet-directed gene transfer $[5,6]$. We hypothesised that transferring an exogenous insulin gene under the control of a powerful promoter would enable islet beta cells to produce more insulin. Perhaps more importantly, the additional insulin produced should be secreted in a normally regulated fashion capitalising on the existing beta cells subcellular organelles and molecular machinery that regulate physiologic insulin synthesis and secretion.

\section{Materials and methods}

Isolation of human pancreatic islets. Human islets were isolated from pancreata $(n=6)$ obtained through the local organ procurement organisation. The pancreas was digested following the intraductal injection of collagenase (Liberase, Roche, Nutley, N.J., USA) at a concentration of $1.66 \mathrm{mg} / \mathrm{ml}$ in Hanks' balanced salt solution. Liberated islets were purified on continuous density gradients (Cellgro/Mediatech, Hernburn, Va., USA) using the COBE centrifuge. Islet fractions with more than $90 \%$ purity were cultured in CMRL-1066 medium (Cellgro/Mediatech) supplemented with $10 \%$ endotoxin-free fetal calf serum (FCS, Cellgro/Mediatech), antibiotic/antimycotic solution (GibcoBRL, Grand Island, N.Y., USA) in a humidified $5 \% \mathrm{CO}_{2}$ incubator at $24^{\circ} \mathrm{C}$.

Islet gene transfer. A recombinant, replication-deficient adenoviral vector (E1-deleted, human adenovirus serotype 5 backbone) was used to transfer the proinsulin gene or beta-galactosidase gene to human pancreatic islets. In both cases, transgene expression was under the control of a CMV promoter and upstream of a polyadenylation signal. Adenoviral vectors were produced and expanded by infection of 293 cells and titred by plaque assay ( $\mathrm{pfu} / \mathrm{ml})$. Purified islets were exposed to adenoviral vectors for $16 \mathrm{~h}$ at 1000:1 (pfu:cell). Islets were washed three times with Hanks' Balanced Salt Solution (HBSS) and then transplanted or re-cultured until assayed. To evaluate the efficiency of gene transfer, LacZ gene product expression was monitored by staining whole islets, islet sections or dispersed islet cells, using $X$-gal solution (5-bromo-4-chloro-indolyl- $\beta$ $D$-galactopyranoside). To assess the expression of the transferred insulin gene, we analysed insulin content (insulin vs total protein) in the control and Ad-Ins-transduced human islets using the micro-BCA protein assay and the human insulin radioimmunoassay (RIA).

In vitro islet perifusion assay. To assess islet function in vitro, 100 islets were hand-picked under a dissecting microscope and placed in a plastic perifusion chamber (Millipore, Bedford, Mass., USA). The perifusion apparatus consisted of computercontrolled fast-performance HPLC system (Water 625 LC System) which allowed programmable rates of flow and glucose concentration in the perifusate, a water bath $\left(37^{\circ} \mathrm{C}\right)$ and fraction collector (Water Division of Millipore). The perifusate for the perifusion assay was Krebs buffer ( $\mathrm{pH}$ 7.4) containing $2.2 \mathrm{mmol} / \mathrm{l} \mathrm{Ca}^{2+}, 0.25 \%$ of bovine serum albumin and was equilibrated with $95 \% \mathrm{O}_{2}$ and $5 \% \mathrm{CO}_{2}$. After 30 to $40 \mathrm{~min}$ of pre-perifusion in the absence of substrate, the glucose concentration in the perifusate was increased by an "up-ramp" from 0 to $26 \mathrm{mmol} / \mathrm{l}$ (over a 26-min period), followed by a glucose "down ramp" from 26 to $0 \mathrm{mmol} / \mathrm{l}$. Glucagon secretion was then stimulated by an amino acid mixture containing a physiological concentration of 19 amino acids excluding glutamine that was added separately. At the end of each experiment, islets were also tested for maximum insulin secretion through $\mathrm{KCl}$ mediated depolarisation by introducing $30 \mathrm{mmol} / \mathrm{KCl}$ into the perifusate. Samples were collected at 1-min intervals throughout the assay for subsequent insulin and/or glucagon measurement by RIA.

In vivo islet transplantation. To evaluate the potency of islet function in vivo, isolated human islets were transplanted into immunodeficient NOD-Scid mice, which were rendered diabetic by injecting the beta cell toxin streptozotocin (Zanosar, Upjohn, Kalamazoo, Mich., USA, $150 \mathrm{mg} / \mathrm{kg}$ i.p. on day 0 and $2)$. Diabetes was defined as an increased blood glucose concentration (>350 mg/dl) for two consecutive days. To assess whether Ad-Ins modification improved the function of islets in vivo, we titrated the mass of islets transplanted (250, 500 and 1000 islets equivalent) under the kidney capsule of STZ-diabetic NOD-Scid mice. Glucose concentrations were monitored daily during the first month and twice weekly thereafter. Intravenous glucose tolerance tests (IVGTT, $5 \mathrm{~g} / \mathrm{kg}$ of glucose) were done 1 to 3 months after islet transplantation. At the end of the experiment (100 to 120 days post-transplantation), the kidney bearing the transplanted islets was removed to document whether the islet graft was responsible for the maintenance of normoglycaemia.

Histological analysis. For electron microscopic examination, isolated islets were washed twice with cold PBS, fixed in $2 \%$ glutaraldehyde in $0.1 \mathrm{~mol} / \mathrm{l}$ sodium cacodylate overnight at $4^{\circ} \mathrm{C}$. Then tissue was rinsed in $0.1 \mathrm{~mol} / \mathrm{l}$ sodium cacodylate buffer and post-fixed with $2 \%$ osmium tetroxide, dehydrated in graded ethanol, and embedded in Epon. $70 \mathrm{~nm}$ thin sections were picked on nickel grids and the surface of the section was itched with $1 \%$ Sodium meta per iodate. Sections were rinsed in deionized water and non-specific sites were blocked with $1 \%$ Ovalbumin $+0.2 \%$ cold water fish skin gelatin for an hour at room temperature. Sections were incubated with antibody (insulin) overnight, washed in PBS and transferred to $10 \mathrm{~nm}$ gold anti-rabbit for $1 \mathrm{~h}$. After washing the grids in deionized water they were examined with JEOL JEM 1010 electron microscope after uranyl acetate and bismuth subnitrite staining. 
For light microscopic examination, kidneys bearing islet grafts were fixed in Bouin's solution or immediately snapfrozen (stored at $-80^{\circ} \mathrm{C}$ ). Bouin's-fixed tissues were processed for routine histology and stained with hematoxylin and eosin (HE) or aldehyde fuchsin (AF). For immunohistochemical analysis of frozen tissues, serial sections $(6 \mu \mathrm{m})$ were stained for islet hormones with: anti-insulin and anti-glucagon antibodies (Pharmingen, San Diego, Calif., USA). Antibodies conjugated with $\mathrm{Cy} 2$ or Cy3 (Jackson IRL, West Grove, Pa., USA) were used as secondary antibody. Control experiments were carried out, omitting the primary antibody.

Statistical analysis. Student's t test was used to compare means, and chi-square analysis to compare proportions. A $p$ value of $\leq 0.05$ was considered statistically significant.

\section{Results}

Efficiency of gene transfer and its effect on islet insulin content. To evaluate the efficiency of gene transfer, LacZ gene product expression was assessed by staining whole islets, islet sections or dispersed islet cells, using X-gal solution. Whole islets showed strongly positive staining for $\beta$-galactosidase after $24 \mathrm{~h}$ of in vitro culture. However, upon histological examination of tissue sections of transduced islets stained with $\mathrm{X}$-gal solution, only cells at the periphery of the islet complex stained positively, indicating that islet cells in the core of the islets had not been effectively transduced by the LacZ transgene-bearing adenovirus. Cell counts of X-gal-stained cells in dispersed single cells (prepared by digestion of the Ad-lacz transduced islets with $0.25 \%$ EDTA-trypsin) showed that 31 to $44 \%$ (mean $37 \pm 4 \%$ ) of the islet cells were transduced.

To evaluate the effect of the insulin gene transfer on insulin production, insulin content $(\mu \mathrm{g} / \mathrm{mg}$, corrected for total protein) of control, Ad-lacz and AdIns-transduced islets were analysed with three different islet preparations ( $n=3$, all with purity $\geq 95 \%$ ). The Ad-Ins-transduced human islets contained 89.3 $35 \mu \mathrm{g} / \mathrm{mg}$ of insulin (8.9\% of total protein, Fig. 1). This represents a significant increased (45\% increase) compared with $61.1 \pm 21 \mu \mathrm{g} / \mathrm{mg}(6.1 \%)$ in the untreated control preparations and $56.6 \pm 21 \mu \mathrm{g} / \mathrm{mg}(5.6 \%)$ in the Ad-LacZ transduced islets (both $p<0.05$ ).

In vitro islet function. A total of six in vitro islet perifusion experiments with six different islet preparations were done in this study. For each islet preparation, islet perfusion was done with islets paired with either control and Ad-lacz islets $(n=3)$ or control and Ad-Ins islets $(n=5)$. There was no difference in insulin secretion comparing Ad-lacz transduced islets with untreated control islets (Fig. 2A), indicating that viral infection of islets did not alter in vitro islet function. In contrast, although showing a similar basal concentration of insulin secretion, Ad-Ins-transduced islets showed an average sixfold increase in insulin secretion, whereas control islets showed only an average

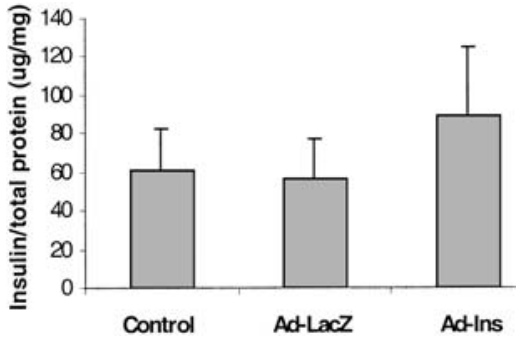

Fig. 1. Insulin content of isolated human islets. Insulin and total protein of controls and Ad-Ins-transduced islets were measured and were expressed as $\mu \mathrm{g}$ insulin per mg of total protein (i.e., insulin content corrected for total protein). The mean values from three different islet preparations show an increased insulin content of the Ad-Ins-transduced islets compared with those of the controls $(p<0.05)$

threefold increase in response to glucose stimulation (Fig. 1B). Maximally stimulated by $\mathrm{KCl}$ depolarisation, the insulin transduced islets responded with a peak insulin release 45-fold higher than the base line, as compared with only an 18-fold increase by the control islets. Thus, the stimulation index (SI) of insulin release from the insulin-transduced islets was two to threefold higher than control islets $(p<0.05)$. To estimate the total amount of insulin secreted from islets during the assay, total insulin secreted was calculated (i.e., AUC: area under curve). Ad-Ins-transduced islets secreted more $(p<0.05)$ insulin, with an average of AUC increasing to $172 \%$ compared to control islets $(100 \%)$.

Both control and insulin-transduced islets showed a normal pattern of glucagon secretion. When the glucose concentration in the perifusate was increased from 0 to $26 \mathrm{mmol} / \mathrm{l}$, glucagon secretion decreased to its nadir, indicating that high glucose effectively inhibited glucagon secretion. However, when the glucose concentration in the perifusate was decreased from 26 to $0 \mathrm{mmol} / \mathrm{l}$, glucagon secretion approximately doubled. Furthermore, when islets were exposed to $15 \mathrm{mmol} / \mathrm{l}$ physiological amino-acid mixture, both control and insulin-transduced islets had a maximal glucagon release with a peak concentration at least five to six times higher than the basal concentration (Fig. 2C). Also, both control and Ad-Ins islets secreted glucagon when depolarized by $\mathrm{KCl}$. Amino acids also caused a transient insulin release from the insulin-transduced islets (Fig. 2C). This phenomenon was conceivably a result of $\alpha$ cells being transduced with the insulin gene, thus causing insulin to be synthesised in the $\alpha$ cells and co-localised and released together with glucagon.

In vivo islet function. Immunoincompetent NOD-Scid mice readily accept either allogeneic or xenogeneic transplants and thus, provide ideal hosts in which to study the efficiency of human islet function without the confounding issue of immunologic rejection. All mice receiving 1000 control islets became normo- 
Fig. 2A-C. Insulin and glucagon secretion from islets during in vitro islet perifusion assay. Isolated islets (100 islets) were preperifused for 30-40 min with the perifusate in the absence of glucose, and then the glucose concentration in the perifusate was increased by an "up-ramp" from 0 to $26 \mathrm{mmol} / \mathrm{l}$ (over a $26 \mathrm{~min}$ period), followed by a glucose "down-ramp" from 26 to $0 \mathrm{mmol} / \mathrm{l}$. At the end of each experiment, islets were also tested for maximum insulin secretion through $\mathrm{KCl}$ mediated depolarisation. A Comparison of the mean values (from 3 paired experiments) of insulin secreted from control (curve with filled circles) versus Ad-LacZ transduced islets (curve with open circles). B Comparison of the mean values (from 5 paired experiments) of insulin secreted from control (curve with filled circles) versus AdIns-transduced islets (curve with open circles). $\mathbf{C}$ One representative of glucagon secretion from islets stimulated by a mixture of amino acids, showing a simultaneous release of insulin from the Ad-Ins-transduced islets
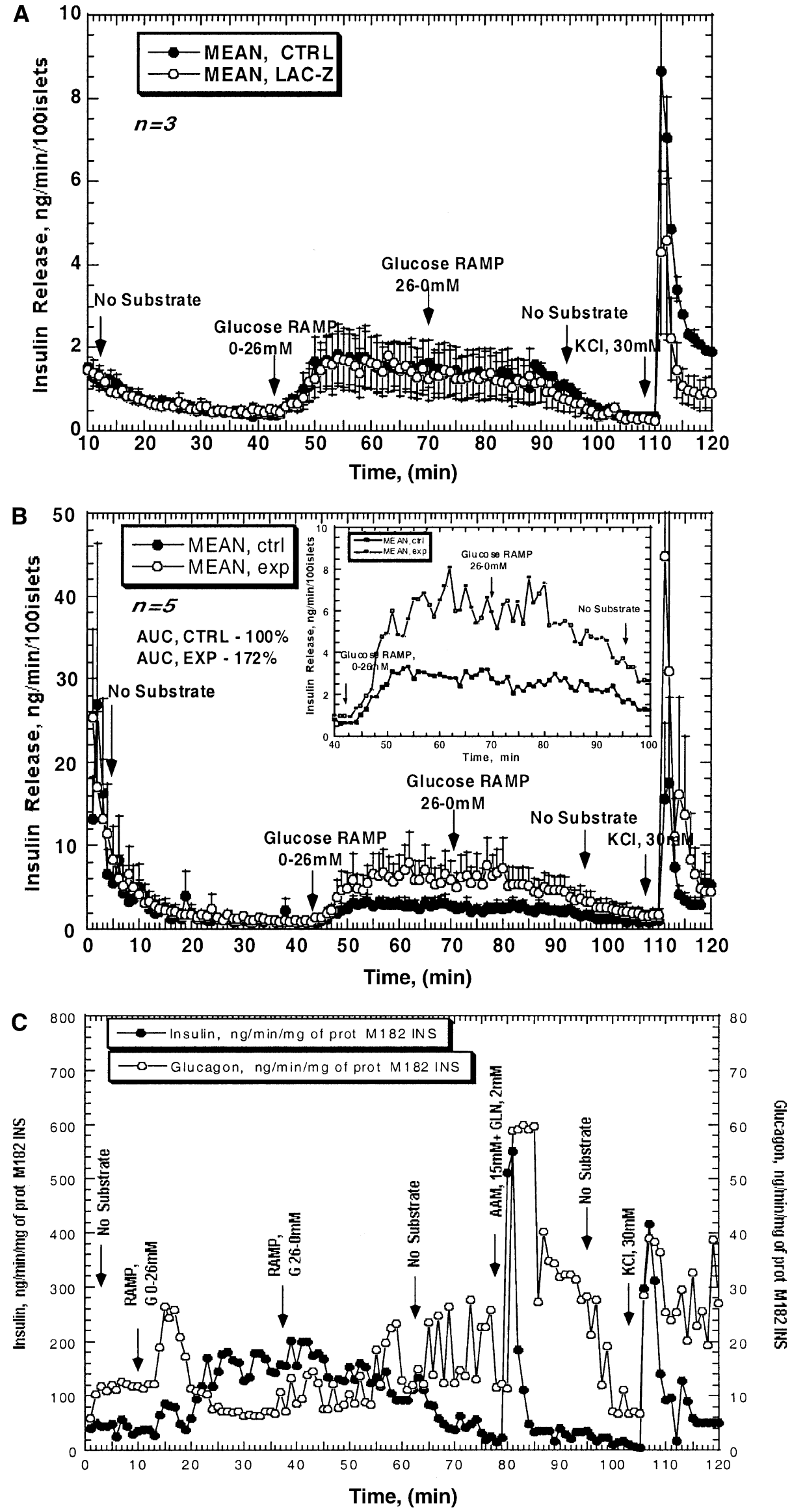

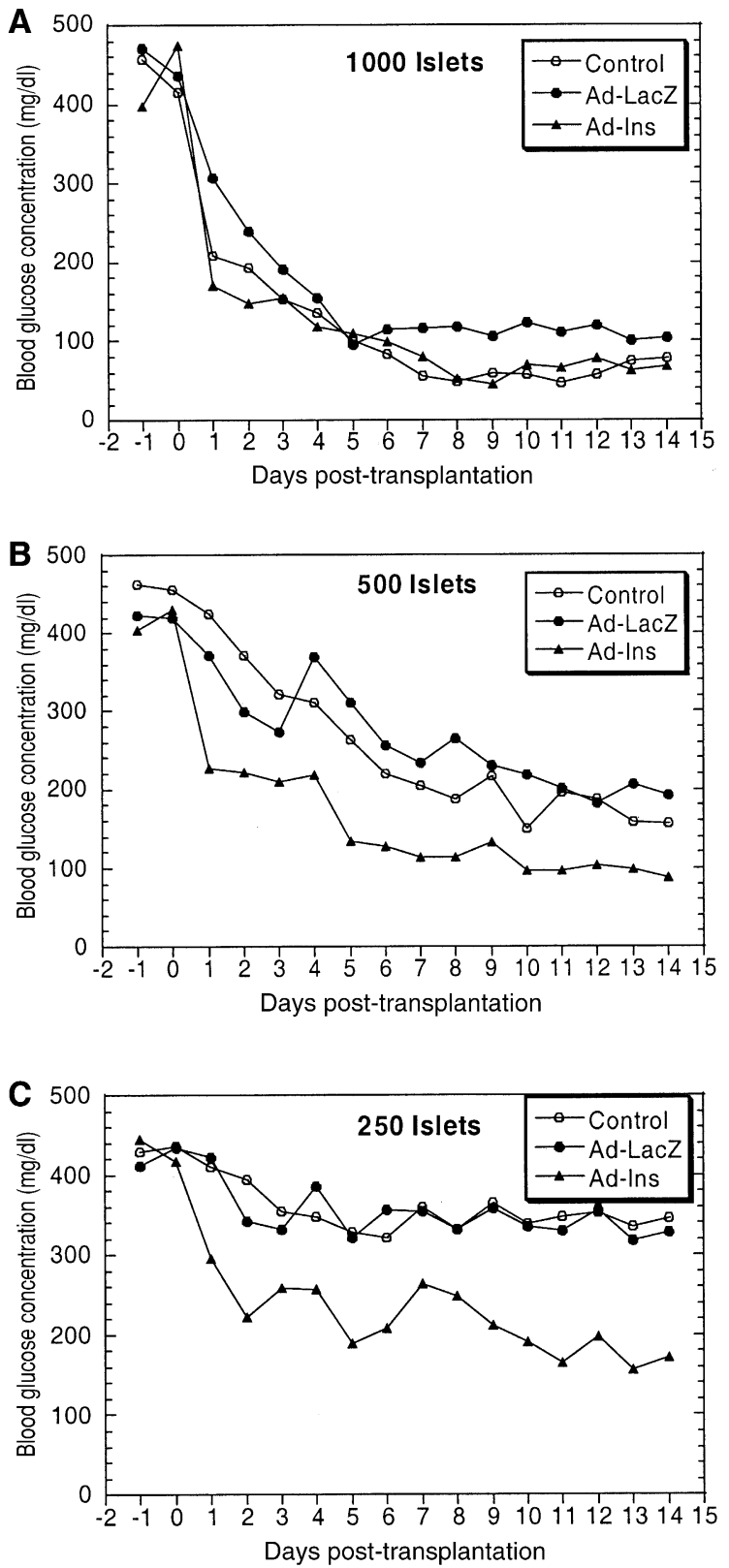

Fig. 3A-C. The blood glucose concentrations of diabetic Scid mice post-transplantation. Isolated human islets with various islet mass [1000 (A), $500(\mathbf{B})$ or $250(\mathbf{C})$ islets] were transplanted under the kidney capsule of STZ-diabetic Scid mice. The curves show the mean values (6-8 mice per group) of blood glucose concentrations of diabetic mice receiving control (open squares), ad-LacZ (filled circles) or Ad-Ins-(filled triangles) islets, during the first two weeks post-transplantation

glycaemic within 3 days after islet transplantation (Fig. 3A). However, when the transplanted islet mass was reduced to 500,7 to 10 days were required for the control mice to become normoglycaemic (Fig. 3B). At a dose of 500 islets, Ad-Ins-transduced grafts normalised blood glucose more $(p<0.05)$ rapidly than untreated control or Ad-lacz treated grafts. This was evident in the mean glucose at 1 week for these groups ( $114 \pm 70$ vs $201 \pm 111$ and $235 \pm 95$, respectively). None of the mice receiving 250 control islets became normoglycaemic at any time after transplantation, and in fact all mice continued to lose weight and eventually died between 2 to 4 weeks after transplantation. In contrast, normoglycaemia was achieved reproducibly using Ad-Ins-transduced islets when a dose of 250 islets was administered (Fig. 3B,C). At this dose, each of eight recipients eventually developed normoglycaemia versus only 0 of 6 untreated controls and 0 of 8 recipients of Ad-lacz treated grafts $(p<0.01)$. Once animals became normoglycaemic, they all remained so for as long as they were monitored up to $>100$ days posttransplantation). However, when the islet graft-bearing kidney was removed by nephrectomy, diabetes quickly recurred (glucose concentration $>350 \mathrm{mg} / \mathrm{dl}$ ) within 3 days.

Transgene expression in adenoviral transduced islets. Electron microscopic examination of islets with antiinsulin antibody showed normal subcellular structures in both control and virally infected islets (Fig. 4A-C), but clearly with more insulin granules in the Ad-Instransduced islets (Fig. 4C). X-gal staining of islet graft showed long-term ( $>100$ days) expression of $\beta$-galactosidase in the Ad-lacz transduced islets transplanted under the kidney capsule of diabetic mice (Fig. 4D,E). Immunohistological examination of islet grafts with anti-islet hormone antibodies showed an increased intensity of fluorescence for insulin in the Ad-Ins-transduced islets compared with the control islets (Fig. 4F,G). Double-staining in these islet grafts with anti-insulin (red) and anti-glucagon (green) antibodies showed double positive cells (orange) in the Ad-Ins-transduced islet grafts (Fig. 4G) but not in the control islet grafts (Fig. 4F), thus indicating that some $\alpha$ cells were transduced with the insulin gene.

\section{Discussion}

Gene therapy has been proposed as a probable strategy to replace insulin secretion in Type 1 diabetes $[7,8]$. One conceptually simple approach is the transfer of an exogenous insulin gene into non-beta cells, such as hepatocytes, muscle cells or other cell lines $[9,10]$. However, due to the extreme complexity of beta-cell physiology, it is quite difficult to induce nonbeta cells to produce and secrete appropriate amounts of insulin in response to changes in blood glucose, that adequately mimic the native beta cell. Some progress has been made by using a glucose controllable promoter or by transferring multiple genes into surrogate cells $[11,12,13]$. Nevertheless, with the current knowledge and technology, it is not likely that genetically engineered perfectly insulin-regulating "pseudo beta-cells" will be available for large-scale clinical use in the near future. 

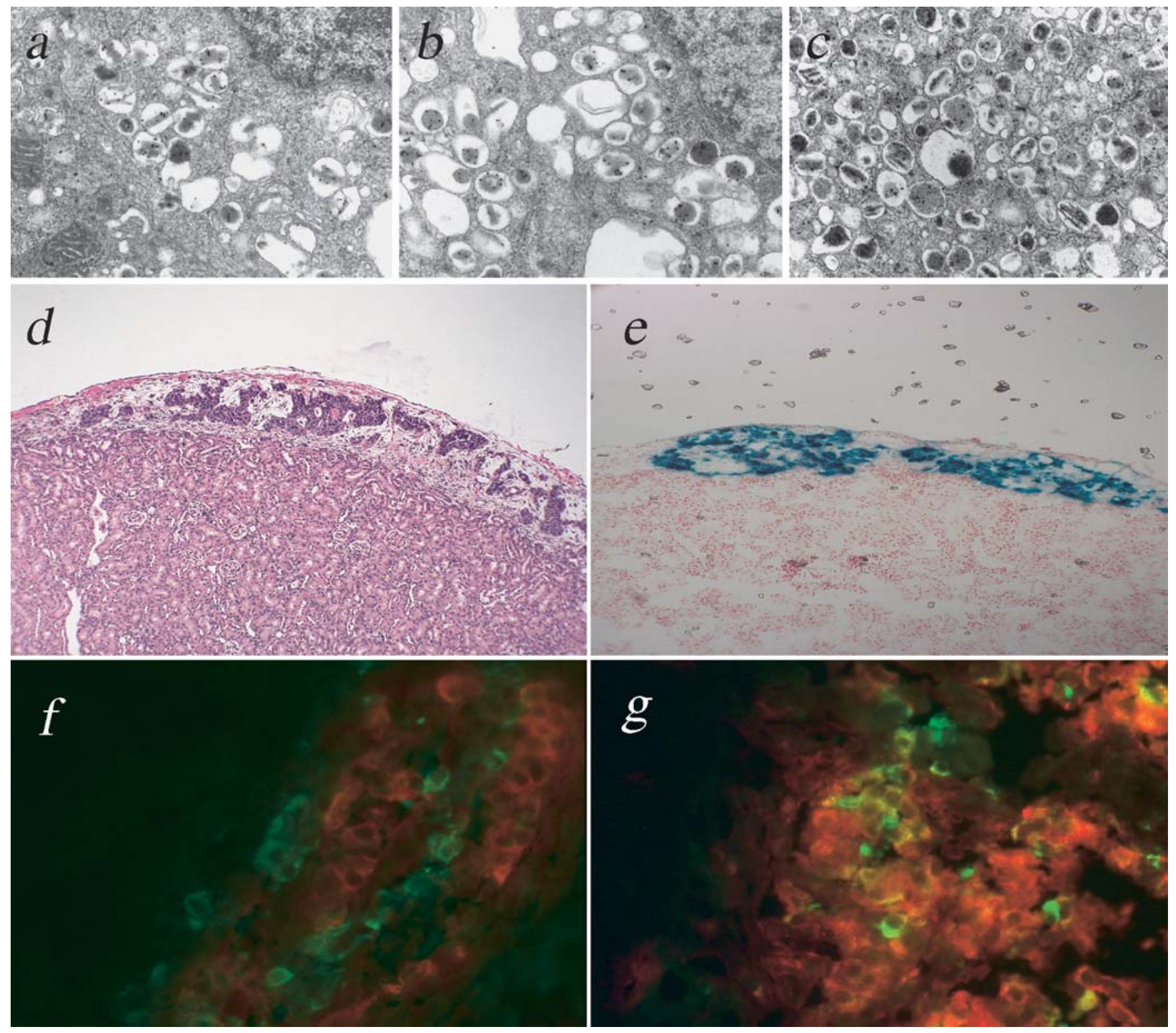

Fig. 4A-G. Histological analyses of isolated human islets and islet grafts. Electron microscopic examination shows subcellular structures including insulin granules stained with anti-insulin antibody (gold particles) of control (A), ad-LacZ (B) and Ad-Ins $(\mathbf{C})$ islets. Light microscopic examination shows the ad-LacZ islets under the kidney capsule of diabetic mice 100 days post-transplantation, stained with $\mathrm{H} / \mathrm{E}$ (D) or X-gal solution (E), indicating a long-term LacZ transgene expression (blue) in the ad-LacZ islets. Fluorescence microscopic examination of the kidneys bearing islet graft stained with anti-insulin (red) and anti-glucagon (green) antibodies shows hormone positive cells in the control (F) and the Ad-Ins islet graft $(\mathbf{G})$, but with some double positive cells (orange) seen only in the latter

We have explored a strategy with equal conceptual simplicity: augmentation of the regulated insulin secretory capacity of an islet graft, by insulin gene transfer to the graft before transplantation. Our data suggest that insulin gene transfer directly to isolated

islets using a viral vector encoding the human proinsulin gene, generates islet beta cells that produce more insulin per cell than untreated cells. Since this approach capitalises on the beta cell's existing subcellular organelles and molecular machinery for precise glucose-regulated insulin secretion, the additional insulin produced is released in a normally regulated manner. Our in vitro results indicate that Ad-Ins-transduced islets show superior function in terms of insulin production and secretion. Ad-Ins-transduced islets show an increase in glucose-induced insulin secretion; in addition the amount of basal insulin secretion and the overall pattern of insulin secretion from the Ad-Ins-transduced islet appeared completely normal. Ad-Ins-transduced islets also achieved normal glucose homeostasis in vivo after transplantation. Transplantation of a large number of these islets did not result in recipient hypoglycaemia, confirming that Ad-Instransduced islets secrete insulin in an appropriately regulated manner. 
Our approach should be considered in the context of normal beta-cell physiology. In normal beta cells, insulin contributes about $10 \%$ of the total cellular dry digest [14]. Transfer of an exogenous insulin gene under control of a powerful viral promoter, forces beta cells to produce even more insulin. Whether there is an upper limit for the amount of insulin that a beta cell can produce without negative consequences is not known. It remains to be seen, for example, how long Ins-transduced beta cells can maintain a supra-normal function without encountering a pathological penalty. We found that insulin over-expression was not obviously deleterious to transplanted beta cells as indicated by the efficient establishment of normoglycaemia, and more importantly, once normoglycaemic, recipients of Ad-Ins-transduced islets remained so for more than 100 days without evidence of deterioration in graft function. Moreover, histological examination showed normal islet graft morphology and the presence of abundant insulin

There are additional issues regarding the potential clinical application of this strategy. First, we selected an adenoviral vector for gene delivery to establish proof-of-principle of the concept that islet function can be enhanced by insulin gene transduction. For clinical purposes, however, adenoviral vectors carry the known disadvantages of potent immunogenicity, potential islet toxicity, and lack of host cell genome integration [15]. Alternative vectors that might be better for clinical application include adeno-associated virus and lentivirus, as each has been found to infect non-dividing cells, including pancreatic islet cells, and each can integrate into the nuclear DNA of infected cells, thus promising more stable and durable transgene expression $[16,17]$. Each of these viral vectors is also less immunogenic than adenovirus.

Second, when isolated islets are exposed to an adenoviral vector, all islet cells including $\alpha$ cells are transduced. Although the characteristics of glucagon secretion from Ad-Ins-transduced islets appear normal, a small amount of insulin release (presumably from Ad-Ins-transduced $\alpha$ cells) was observed when these islets were stimulated by an amino acid mixture known to stimulate glucagon secretion. This would probably be a concomitant event for any form of $\alpha$-cell stimulation. This raises the theoretical concern of hypoglycaemia during fasting and exercise. However, we did not observe hypoglycaemia in the recipients of Ad-Ins-transduced islets in our in vivo transplant model. This could have been due to the small amount of insulin released by transduced $\alpha$ cells, and the small proportion of the islet that they comprise, especially in the setting of normal glucagon release and the presence of other intact counter regulatory measures. To avoid this undesired effect, insulin promoter could be used instead of CMV promoter. The use of insulin promoter can render the Ad-Ins-transduced islets able to release more insulin in a highly regulated manner and also synthesise more insulin in response to the change of blood glucose concentration.

Third, with the rapidly evolving success in islet transplantation, a major obstacle preventing greater application of this approach to treat Type 1 diabetes will be an inadequate source of islets for transplantation, a problem compounded by the apparent need for multiple donors for each recipient. Although it is sometimes possible to restore normoglycaemia after transplantation of islets from a single donor, it is clear that in many cases, one pancreas yields an insufficient islet mass for this to be accomplished. In addition, in many cases, islet preparations from one pancreas that yield only a small islet mass (i.e. <200 000 islet equivalents) are deemed inadequate to justify a transplant and are therefore discarded. Thus our approach to augment the insulin secretory capacity of transplanted islets, if applied successfully clinically, might not only permit more consistent reversal of diabetes using islets procured from a single donor, but could also make more preparations suitable for transplantation.

Of note, islet gene transfer was carried out using an islet-virus co-culture technique. This approach results in only partial islet transduction, with about one third of the cells (37\%) expressing the transgene. If all islet cells could be transduced, further increased in graft efficiency (up to threefold further, or a total improvement of six- to ninefold, compared with control islets) would be observed along with further reductions in minimal islet mass required for the complete reversal of diabetes. We are currently assessing this possibility of Ad-Ins-vector delivery by vascular perfusion of the pancreas, a technique we have found to result in transgene expression in nearly all islet endocrine cells [18]. If maximal transduction efficiency can be achieved in this way, it could even be possible to reverse diabetes with islets isolated from only a portion of the pancreas. The distal pancreas from living donors has been used successfully as a segmental vascularised graft, and recently the donor procedure has been reported using a minimally invasive approach $[19,20]$. Thus, the consideration of live donors as a source of islets to treat Type 1 diabetes is not unreasonable if the efficiency of islet function and engraftment can be improved. If the approach that we have described becomes a practical method, it could provide a reasonable solution to the organ shortage by supplying islet tissue until other strategies such as stem-cell derivation of beta cells or xenogeneic sources of islet tissue can be refined.

Acknowledgements. We thank B. Koeberlein, H. Collins and N. Shah for their superb technical supports and Dr. A. Naji and Dr. C. Barker for reviewing the manuscript. This work is funded by NIH 2P01DK49814-06 and the JDRF. 


\section{References}

1. Shapiro AM, Lakey JR, Ryan EA et al. (2000) Islet transplantation in patients with diabetes using glucocorticoidfree immunosuppression. N Eng J Med 343:230-238

2. Ryan EA, Lakey JR, Rajotte RV et al. (2001) Clinical outcomes and insulin secretion after islet transplantation with the Edmonton protocol. Diabetes 50:710-719

3. Ricordi C (1996) Human islet cell transplantation: new perspective for an old challenge. Diabetes Rev 4:356369

4. Weir GC, Bonner-Weir S (1997) Perspectives in Diabetes: scientific and political impediments to successful islet transplantation. Diabetes. 46:1247-1256

5. Csete ME, Benhamou PY, Drazan KE et al. (1995) Efficient gene transfer to pancreatic islets mediated by adenoviral vectors. Transplantation. 59:263-268

6. Weber M, Deng S, Kucher T et al. (1997) Adenoviral transfection of isolated pancreatic islets: a study of programmed cell death (apoptosis) and islet function. Journal of Surgical Research. 69:23-32

7. Giannoukakis N, Rudert WA, Robbins PD, Trucco M (1999) Targeting autoimmune diabetes with gene therapy. Diabetes 48, 2107-2121

8. Levine F (2001) Gene therapy for diabetes Front Biosci 6: D175-D191

9. Newgard CB (1994) Cellular engineering and gene therapy strategies for insulin replacement in diabetes. Diabetes 43:341-350

10. Lipes MA, Davalli AM, Cooper EM (1997) Genetic engineering of insulin expression in nonislet cells: implications for beta-cell replacement therapy for insulin-dependent diabetes mellitus. Acta Diabetol 34:2-5
11. Lee HC, Kim SJ, Kim KS, Shin HC, Yoon JW (2000) Remission in models of type 1 diabetes by gene therapy using a single-chain insulin analogue. Nature 408:483-488

12. Davalli AM, Galbiati F, Bertuzzi F et al. (2000) Insulinsecreting pituitary GH3 cells: a potential beta-cell surrogate for diabetes cell therapy. Cell Transplant 9:841-851

13. Cheung AT, Dayanandan B, Lewis JT et al. (2000) Glucose-dependent insulin release from genetically engineered K cells. Science 290:1959-1962

14. Bedoya FJ, Matschinsky FM, Shimizu T, O’Neil JJ, Appel MC (1986) Differential regulation of glucokinase activity in pancreatic islets and liver of the rat. $\mathrm{J}$ Biol Chem 261:10760-10764

15. Leibowitz G, Beattie GM, Kafri T et al. (1999) Gene transfer to human pancreatic endocrine cells using viral vectors. Diabetes 48:745-753

16. Flotte T, Agarwal A, Wang J et al. (2001) Atkinson M. Efficient ex vivo transduction of pancreatic islet cells with recombinant adeno-associated virus vectors. Diabetes 50:515-520

17. Ju Q, Edelstein D, Brendel MD et al. (1998) Transduction of non-dividing adult human pancreatic beta cells by an integrating lentiviral vector. Diabetologia 41:736-739

18. Deng S, Kucher T, Chen H, Brayman KL (1998) Intraarterial delivery of adenoviral vector to intact pancreata achieves highly efficient gene transfer to human pancreatic islets. Diabetes. 47: A67 (Abstract)

19. Lillemoe KD, Kaushal S, Cameron JL, Sohn TA, Pitt HA, Yeo CJ (1999) Distal pancreatectomy: indications and outcomes in 235 patients. Ann Surg 229:693-700

20. Gruessner RW, Kandaswamy R, Denny R (2001) Laparoscopic simultaneous nephrectomy and distal pancreatectomy from a live donor. J Am Coll Surg 193:333-337 